\title{
Clinicopathological Study of Testicular Tumors
}

\author{
${ }^{1}$ Sharmila P Surhonne, ${ }^{2}$ Ashwin P Surhonne, ${ }^{3}$ Alka V Gosavi, ${ }^{4}$ Shobhana R Agashe, ${ }^{4}$ Molly A Phansopkar
}

\begin{abstract}
Objective: Clinicopathological analysis of testicular tumors as per World Health Organisation (WHO) classification.
\end{abstract}

Materials and methods: All consecutive cases of testicular tumors diagnosed in the department of pathology for five year were included in this study.

Results: During the span of five years, total 59 cases of testicular tumors were diagnosed. Scrotal mass or swelling was the predominant mode of presentation. Germ cell tumors constituted $89.8 \%(n=53)$ of all testicular neoplasms in which seminoma $32.2 \%$ and teratocarcinoma $13.4 \%$ were present. Yolk-sac tumor (5.1\%) was the commonest testicular neoplasm in children while lymphoma (8.5\%) was the predominant neoplasm in elderly population. One case of leukemic infiltration of testis $(1.7 \%)$ in a known patient of acute lymphocytic leukemia after chemotherapy was also observed.

Conclusion: In this study clinical presentation, age,and frequency of testicular tumors, with few exceptions are similar to other studies from different parts of country, confirming similarity in international literature.

Keywords: Frequency, Germ cell tumor, Testicular tumor, Testis

How to cite this article: Surhonne SP, Surhonne AP, Gosavi AV, Agashe SR, Phansopkar MA. Clinicopathological Study of Testicular Tumors. Int J Med Sci 2018;4(3):63-70.

Source of support: Nil

Conflict of interest: None

\section{INTRODUCTION}

Cancers of the testes is the second most frequent male genital cancer. The worldwide incidence of testicular cancer has doubled over the last 40 years. In most countries, testicular cancer is rare, with an age-standardized incidence rate ranging from about $1 / 100,000$ in Asian, African/African-American populations to 9.2/100,000 in Denmark). In Indian population (Bombay), the incidence is $0.9 / 100,000$. $^{1}$

\footnotetext{
${ }^{1,3}$ Professor and HOD, ${ }^{2}$ Undergraduate Student, ${ }^{4}$ Ex. Professor

${ }^{1}$ Department of Pathology, RajaRajeswari Medical College and Hospital, Bengaluru, Karnataka, India

${ }^{2}$ Oxford Medical College and Hospital, Bengaluru, Karnataka, India

${ }^{3,4}$ Department of Pathology, Government Medical College, Miraj, Sangli, Maharasthra, India
}

Corresponding Author: Sharmila P Surhonne, Professor and HOD, Department of Pathology, RajaRajeswari Medical College and Hospital, Bengaluru, Karnataka, India, Mobile: +919448473489, e-mail: ashwin.ashwin45@gmail.com
Approximately $95 \%$ of malignant tumors arising in the testes are germ cell tumors (GCT). ${ }^{2}$ The cause of GCT in most cases is unknown. Cryptorchidism, familial predisposition, GCT in contralateral testis, gonadal dysgenesis and androgen in sensitivity syndrome and male infertility are associated with elevated risk of testis cancer. ${ }^{2}$ Most of the established risk factors are related to early life events, including cryptorchidism, carcinoma in situ and in utero exposure to estrogens. Occupational, lifestyle, socio-economic and other risk factors have demonstrated mixed associations with testicular cancer.

Most of the GCT in adults appear to arise from the malignant transformation of primordial germ cells (PGCS) or gonocytes. Continuous proliferation of such cells within the seminiferous tubules heals the lesions that is termed intratubular germ cell neoplasia-unclassified type (ITGCNU) or carcinoma in situ (CIS). ${ }^{2,3}$ There is pivotal role of ITGCNU and seminoma in the development of various germ cell tumor types although alternative pathways excluded. The cells of ITGCNU are identical to seminoma cells. ITGCNU is found in almost all cases where residual seminiferous tubule are identified around an invasive GCT. It is also present in $5.8 \%$ cases of cryptorchidism and upto $5 \%$ of testis contralateral to an invasive GCT and also frequently in dysgenetic gonads. About $50 \%$ of patients with ITGCNU on biopsy will develop invasive GCT within 5 years and ultimately in almost all patients ITGCNU will progress to invasive tumors. Rarely in cases with metastatic GCT, ITGCNU may be found in the testis in association with a scar with or without calcification and without any recognized invasive tumor. Such cases are believed to represent burnt out GCT (regression of primary tumor). ITGCNU cells share a number of markers with the pluripotent primordial germ cell/gonadocytes, including placental alkaline phosphatase (CDLAD) and (KIT and OCT 3). ${ }^{3}$

Numerous schemes for classifying GCT have been proposed on the basis of the tumors presumed histiogenesis or their predominant morphology, the classification Dixon and Moore ${ }^{4}$ dominated for sometime. The most widely used are the classification Proposed by Mostofi and Sabin ${ }^{4-7}$ accepted by World Health Organisation (WHO) and British testicular tumor panel. For clinicians standpoint GCT of testis are segregated into seminoma and nonseminomatous by extensively sampling of the tumor as they differ with respect to clinical features, therapy and prognosis. 
Historically urologists and oncologists have categorically rejected the use of fine needle aspiration (FNA) testis for the investigation of patients with presumed testicular neoplasms due to their fear that FNA testis would lead to tumor implantation within the scrotum and there by increased risk of inguinal node metastasis. Since majority of testicular tumors are malignant, FNA testis does not have a recognized and accepted role in establishing the diagnosis of testicular tumor FNA is helpful only for detection GCT of testis at metastatic or cryptorchid site.

The currently recommended staging system for testicular tumor is the AJCC-TNM staging. Testis is the only organ system to date where tumor marker levels are used, as important prognostic factor. ${ }^{1-3}$

Serum tumor marker such as the beta subunit of human chorionic gonadotropin (beta-hCG), alpha fetoprotein (AFP) and lactate dehydrogenase (LDH) have an important role in the management of patients with testicular cancer, contributing to diagnosis, staging and risk assessment, evaluation of response to therapy. Early detection of $\mathrm{LDH}$ is recommended for patients with metastatic disease. ${ }^{2}$

High inguinal orchiectomy is the standard initial treatment for suspected testicular tumor. Appropriate integration of surgery, chemotherapy and radiation therapy in treatment has lead to high cure rates. The introduction of cisplastin-based chemotherapy has revolutionized the management of testicular tumors, with considerable improvement in response rates and excellent outcome reported even in presence of metastatic disease. $^{8-11}$

\section{MATERIALS AND METHODS}

All consecutive cases of testicular tumors diagnosed in the Department of Pathology at Wanless Hospital Miraj for five years were included in this study. Relevant clinical details such as age, clinical presentation and side of involvement of the testis were also recorded from the hospital records.

We have omitted the tumor like lesions of testis, paratesticular tumors and tumors of testicular adnexae in this study. Ten percent formalin was used as preservative and fixative for all specimens. The gross examination of the specimens was performed and adequate representative sections were obtained according to the guidelines provided by Rosai. ${ }^{12}$

Paraffin-embedded sections were stained routinely with haematoxylin and eosin. Special stains like PAS, reticulin, etc., were used in selected cases.

Here an attempt is made to classify the tumors according to the histopathological typing of the testicular tumors published by WHO 2004. Incidence of various tumors encountered in our study is shown in (Table 1).

The age range of testicular tumor in this series was very wide (Table 2), varied from youngest 2 years to oldest 80 years. The age distribution of different tumors was quite peculiar, the germ cell tumors were seen most commonly in the age range of 20 to 49 years. Seminoma was seen most commonly in the age range of 30 to 39 years. Embryonal carcinoma was common in age range 20 to 29 years. Yolk sac tumors was seen in childhood most commonly between 0 to 9 years. Teratocarcinoma was seen commonly in 20 to 29 years of age. No case of germ cell tumors of more than one histological type was seen in childhood or older age group. Lymphoid tumors were seen in old age more commonly than young ones. Patient presented clinically with history of scrotal swelling (94.6\%), pain in abdomen, history of trauma or abdominal swelling as shown in (Table 3).

\section{DISCUSSION}

Testicular tumors have fascinated the pathologists and clinicians alike since initial description over a century ago. The incidence of germ cell tumor of testis has shown a worldwide progressive increase in the 20th century. The incidence of testicular tumors as recorded in literature

Table 1: Individual testicular tumors and their percentage

\begin{tabular}{|c|c|c|}
\hline $\begin{array}{l}\text { Testicular tumors as per WHO } \\
\text { classification }\end{array}$ & $\begin{array}{l}\text { No.of } \\
\text { cases }\end{array}$ & Percentage \\
\hline I Germ cell tumors & 53 & 89.8 \\
\hline a) Tumors of one histological type & 34 & 57.6 \\
\hline 1 Seminoma & 19 & 32.2 \\
\hline 2 Spermatocytic seminoma & 2 & 3.4 \\
\hline 3 Embryonal carcinoma & 5 & 8.5 \\
\hline 4 Yolk sac tumor & 3 & 5.1 \\
\hline 5 Choriocarcinoma & 1 & 1.7 \\
\hline 6 Teratoma & 4 & 6.8 \\
\hline $\begin{array}{l}\text { b) Tumors of more than one } \\
\text { histological type }\end{array}$ & 19 & 32.2 \\
\hline $\begin{array}{l}1 \text { Embryonal carcinoma and } \\
\text { teratoma }\end{array}$ & 8 & 13.4 \\
\hline 2 Teratocarcinoma + yolk sac tumor & 2 & 3.4 \\
\hline $\begin{array}{l}3 \text { Teratocarcinoma }+ \\
\text { choriocarcinoma }\end{array}$ & 1 & 1.7 \\
\hline 4 Teratocarcinoma + seminoma & 2 & 3.4 \\
\hline 5 Embryonal carcinoma + seminoma & 4 & 6.8 \\
\hline 6 Seminoma + Yolk sac tumor & 1 & 1.7 \\
\hline $\begin{array}{l}7 \text { Embryonal carcinoma }+ \\
\text { choriocarcinoma }\end{array}$ & 1 & 1.7 \\
\hline $\begin{array}{l}\text { II Lymphoid and haemopoietic } \\
\text { tumors }\end{array}$ & 6 & 10.2 \\
\hline 1 Lymphoma & 5 & 8.5 \\
\hline 2 Leukemic infiltration & 1 & 1.7 \\
\hline Total & 59 & 100 \\
\hline
\end{tabular}


Table 2: Age distribution of Individual testicular tumors and their percentage $(N=59)$

\begin{tabular}{|c|c|c|c|c|c|c|c|}
\hline Testicular tumors & $0-9$ & $10-19$ & $20-29$ & 30-39 & $40-49$ & $50-59$ & $>60$ \\
\hline Seminoma & & & 4 & 8 & 5 & 1 & 1 \\
\hline Spermatocytic seminoma & & & & 1 & & 1 & \\
\hline Embryonal carcinoma & & & 3 & 1 & & & \\
\hline Yolk sac tumor & 2 & 1 & & & & & \\
\hline Choriocarcinoma & & & 1 & & & & \\
\hline Teratoma & 1 & 2 & & & 1 & & \\
\hline Teratocarcinoma & & 2 & 5 & & 1 & & \\
\hline Teratocarcinoma + yolk sac tumor & & & 1 & & 1 & & \\
\hline Teratocarcinoma + choriocarcinoma & & 1 & & & & & \\
\hline Teratocarcinoma + seminoma & & & 1 & & 1 & & \\
\hline Embryonal carcinoma + seminoma & & & 1 & 3 & & & \\
\hline Seminoma + Yolk sac tumor & & & & & 1 & & \\
\hline Embryonal carcinoma + choriocarcinoma & & & 1 & & & & \\
\hline Lymphoma of testis & 1 & 1 & & & & 2 & 1 \\
\hline Leukemic infiltration of testis & 1 & & & & & & \\
\hline Total & 5 & 7 & 17 & 13 & 10 & 5 & 2 \\
\hline Percentage & $8.5 \%$ & $11.8 \%$ & $28.9 \%$ & $22.0 \%$ & $16.9 \%$ & $8.5 \%$ & $3.4 \%$ \\
\hline
\end{tabular}

Table 3: Clinical manifestation of testicular lesions

\begin{tabular}{lll}
\hline Clinical history & No. of cases $(N=93)$ & percentage \\
\hline Scrotal swelling & 88 & $94.6 \%$ \\
h/o trauma & 10 & $10.7 \%$ \\
Pain & 26 & $27.9 \%$ \\
Cryptorchidism & 4 & $4.3 \%$ \\
Abdominal lump & 2 & $2.2 \%$ \\
\hline
\end{tabular}

varies from 0.5 to $2.73 \%$ of all malignant tumors in males and 13.04 to $23.4 \%$ of male uro-genital system tumors. In India, incidence is low i.e., $15.92 \% .{ }^{12,13}$ Mortality rates for testicular cancer are very low, with the 5-year survival rate increasing from about $63 \%$ to more than $90 \%$ during the last 30 years. ${ }^{12,13}$ Testicular tumors are rare, yet they constitute the fourth common cause of death.

In our study testicular tumor accounted for $0.16 \%$ of all surgical specimens and $63.5 \%$ of all testicular lesions. Among the total 59 cases of testicular tumors, $53(89.8 \%)$ were germ cell tumors (GCT) and $6(10.2 \%)$ were cases of lymphoid and haemopoietic tumors.

Average age was found to be 24.7 years which was in concordance with the findingsof Fischer et al. ${ }^{14}$ who found 33.3 years as the average age. We found maximum number of cases in age range 20 to 39 years (15 cases), followed by 13 cases in age range 40 to 49 years. our findings were in concordance with the findings of various other authors The peculiar distribution of different types of testicular tumors in particular age group in this study is similar to Mostofi and Price. ${ }^{6}$

In the present study, 29 cases involved right testis and 27 cases involved left testis. Slight right side preponderance is also noted in other series, Mostofi and Price. ${ }^{6}$

Gupta et al. ${ }^{15}$ and Gupta et al. ${ }^{16}$ and Chandanwale et al. ${ }^{13}$ Embryonal carcinoma which involved left testis predominately. However, bilateral involvement was not observed.

Scrotal swelling was the commonest mode of presentation seen in $84.6 \%$ patients, leaving four cases of maldescended testis. The duration of symptoms varied from 1 months to 15 years. In the study of Chandanwale et al. ${ }^{13}$ duration was varied from 6 months to 10 years. Secondary hydrocele was observed in Chandanwale et al. ${ }^{13}(12 \%)$. Gupta et al. ${ }^{15}(8.8 \%)$ cases We did not come across cases of testicular tumors with secondary hydrocele. History of pain in the present study was noted in only 10 patients $(16.9 \%)$. Gupta et al. ${ }^{15}$ got history of pain in $23.5 \%$ of patients, whereas Tan et al. ${ }^{13}$ found associated pain in $22.6 \%$ of cases. History of trauma was available in seven $(11.8 \%)$ patients. Gupta et al. ${ }^{15}$ noted history of trauma in 7 out of 125 cases $(5.60 \%)$ whereas, Deotra et al. ${ }^{17}$ found history of trauma in $4 \%$ patients. Our findings were in concordance with them.

In present study we found associated lymphadenopathy in three cases (5.1\%). The patients had inguinal, omental and mesenteric lymphadenopathy ( $\mathrm{n}=1$ each). Only omental lymph node showed microscopic evidence of metastasis in a pure case of seminoma. While others showed reactive changes. Mostofi and Davis Jr. ${ }^{18}$ had noticed metastasis in $25 \%$ cases at the time of firstexamination. Gynaecomastia was not seen in any of our cases. Mostofi and Davis Jr. ${ }^{18}$ have noticed gynaecomastia in $2.10 \%$ cases. None of our case had presented with gynecomastia, infertility or gonadal dysgenesis or male pseudohermaphoridism which is an uncommon mode of presentation.

In our study. four cases (6.8\%) of patients had cryptorchidism. 
The percentage of incidence of tumors with maldescended testis varies from 3.6 to $10.7 \%$ (Table 4) incidence of testicular tumor in our series is comparable to Moghe et al. ${ }^{19}$ In our series seminoma is the commonest tumor involving cryptorchid testis' (3 out of 4 cases). The predominence of seminoma in cryptorchid is also noted by Miller and Seljeld ${ }^{20}$ (18 out of 25 cases). Gupta et al. (7 out of 10 cases), Gilbert and Hamilton ${ }^{13}$ reported that no particular tumor is favoured by ectopic testis. Of the four cases of cryptorchid testis three cases are intra abdominal and one case is of undescended testis corrected by orchiopexy risk of development of tumors in abdominal testis is 4 times more than inguinal testis as described by Dixon and Moore, ${ }^{9}$ Collins and Pugh ${ }^{21}$ Gupta, ${ }_{15}^{15}$ and Deotra. ${ }^{17}$ The comparison of frequency of individual testicular tumors with other workers study is depticted in (Table 5).

In GCT of one histological type, seminoma was commonest, it is constituted $32.2 \%$ of all GCT of one histological type and $55.6 \%$ all GCT of testis and 38\% all testicular tumors. Percentage of seminoma in other series ranged from 27.78 to $56.5 \%$. Our findings are

Table 4: The incidence of cryptorchidism in testicular tumors in various studies

\begin{tabular}{ll}
\hline Authors & Percent of tumors in cryptorchid testis \\
\hline Dixon Moore & 10.7 \\
Collin and Pugh & 5.9 \\
Moghe KV & 6.2 \\
Mostofi FK & 3.6 \\
Gupta VP & 8 \\
Shirish & 4 \\
Jodhpur & 5 \\
Pakistan & 8.4 \\
Present & 6.8 \\
\hline
\end{tabular}

slightly less than other workers whereas Gupta et al. ${ }^{16}$ $(27.2 \%)$ who have got even lower percentage. The average age of our series 39.2 years was comparable with other workers which was around 40 years. ${ }^{13}$ The involvement of cryptorchid testis was seen in 3 out of 19 cases of seminoma ( $15.79 \%)$, all with abdominal testis. Metastasis to omental lymph node is seen in one case out of 19 cases of seminomas which histologically showed pure seminoma. Mostofi, and Price ${ }^{6}$ observed metastasis in $10 \%$. According to them pure seminoma metastasises as pure seminoma in $65 \%$ while as embryonal carcinoma and teratoma in $26 \%$ and $4 \%$ cases respectively. Gupta et al. ${ }^{16}$ also noted one case of syncytiotrophoblastic giant cells in their study of 25 semi-nomas. The gross and microscopic findings of seminoma (Fig. 1) in the present study are similar to those described by others ${ }^{6,13,15,16}$ the interstitial diffuse growth pattern is seen in all cases. None of the cases shows intratubular growth pattern. The interstitial growth is more common than intratubular growth in seminoma. ${ }^{6}$

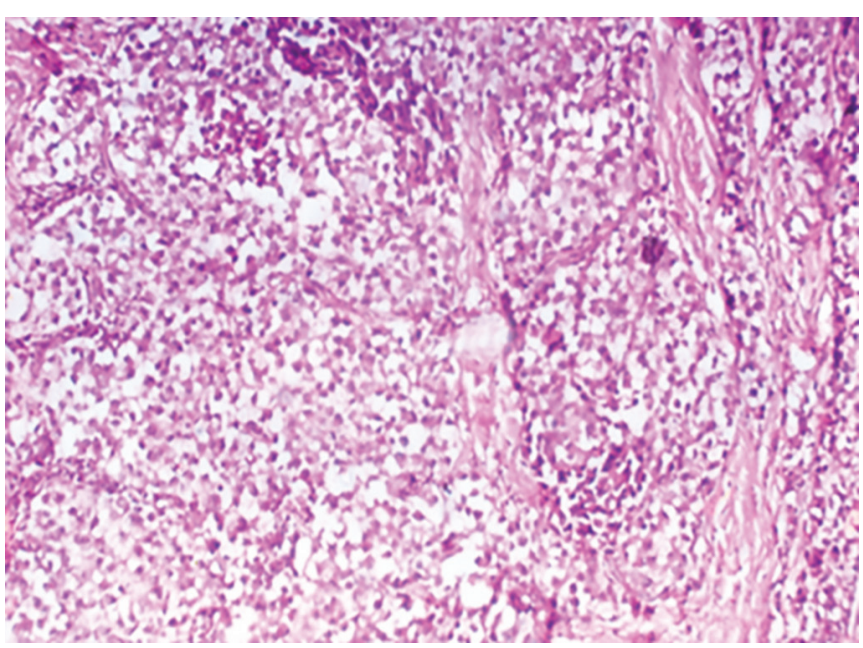

Fig. 1: Classical Seminoma (H and E, 100X)

Table 5: The incidence of different types of testicular tumors in various studies

\begin{tabular}{|c|c|c|c|c|c|c|c|c|c|}
\hline Type of a tumor & $\begin{array}{l}\text { Collin } \\
\text { and } \\
\text { Pugh }^{21}\end{array}$ & $\begin{array}{l}\text { Moghe } \\
\text { et al. }^{19}\end{array}$ & $\begin{array}{l}\text { Mostofi } \\
\text { and } \\
\text { Price }^{6}\end{array}$ & $\begin{array}{l}\text { Gupta } \\
\text { et al. }^{15}\end{array}$ & $\begin{array}{l}\text { Gupta } \\
\text { et al. }\end{array}$ & $\begin{array}{l}\text { Chandanwale } \\
\text { et al. }{ }^{13}\end{array}$ & $\begin{array}{l}\text { Devotra } \\
\text { et al. }{ }^{17}\end{array}$ & $\begin{array}{l}\text { Gill } \\
\text { et al. }{ }^{22}\end{array}$ & $\begin{array}{l}\text { Present } \\
\text { Study }\end{array}$ \\
\hline Germ cell tumor & $85.1 \%$ & 91.5 & 94 & 85.6 & 86.6 & 90 & 99 & 83.5 & 89.6 \\
\hline Seminoma & 40.2 & 41.4 & 32 & 40.8 & 27.7 & 34 & 34 & 56.5 & 32.2 \\
\hline $\begin{array}{l}\text { Spermatocytic } \\
\text { seminoma }\end{array}$ & 7.4 & - & 9 & 9.3 & 3.8 & 4 & - & 1.18 & 9.5 \\
\hline $\begin{array}{l}\text { Embryonal } \\
\text { carcinoma }\end{array}$ & 16.2 & 14.6 & 20 & 16.8 & 15.3 & 16 & 28 & 2.35 & 8.5 \\
\hline Yolk sac tumor & - & 3.1 & - & 4 & 13.3 & 6 & 7 & 7.65 & 5.1 \\
\hline $\begin{array}{l}\text { Teratoma } \\
\text { choriocarcinoma }\end{array}$ & 1.2 & 4.2 & 9 & 4.3 & 24.45 & $\begin{array}{l}12 \\
-\end{array}$ & 7 & 7 & 6.8 \\
\hline $\begin{array}{l}\text { Mixed germ } \\
\text { tumor }\end{array}$ & 17.2 & - & 62. & 22.4 & -4.4 & 18 & 23 & 28.8 & 32.2 \\
\hline lymphoma & 7 & 2.08 & 5 & 22.4 & 4.4 & 6 & 1 & -8.23 & 18.5 \\
\hline $\begin{array}{l}\text { Leukemic } \\
\text { infiltration }\end{array}$ & - & - & - & - & - & - & - & 3.5 & 1.7 \\
\hline Sex cord tumor & - & - & 3 & 0.8 & 1.1 & 4 & 6 & 1.8 & - \\
\hline
\end{tabular}


Lymphocytic infiltration of stroma is described by all workers except Damjanov ${ }^{22}$ who have reported a case of seminoma devoid of lymphoid infiltrate. Granulomatous reaction is noted in 2 out of 19 cases i.e., (10.5\%) Collin and Pugh et al. ${ }^{21}$ have noted granulomatous rection in $40 \%$ cases which was extensive in $16 \%$ cases. Areas of tumor necrosis was seen in two cases of seminoma in this study. These are usually incospicuous but in large tumors they are extensive. The involvement of proximal surgical margin and epididymis is seen in two cases (10.5\%). Mostofi and Price ${ }^{6}$ have described extensive infiltration beyond capsule to scrotal skin, epididymis and spermatic cord in 8\% cases. Only one case out of 19 cases of seminoma, i.e., $5.2 \%$ anaplastic features and $3>$ or $=$ mitosis per high power field. The same tumor showed syncytiotrophoblastic giant cells.(Fig. 2)

Second commonest tumor of GCT category was embryonal carcinoma (Fig. 3) constituting $5 \%$ of all testicular tumors, and, $43.4 \%$ of GCT, $14.7 \%$ GCT of one histoligical type and $94.7 \%$ of GCT more than one histological type the incidence of this tumor in various series showed wide range 4.2 to $37 \%$ of $\mathrm{GCT}^{13-16,21}$ This is due to different interpretation of this term by various authors and inclusion of yolk sac tumor in adult embryonal carcinoma. Different followers of Collin and Pugh classification who do not use term embryonal carcinoma actually give higher incidence of this tumor as it includes teratocarcinoma such as, Moghe et al. ${ }^{19}$ (36.4\%) our findings are slightaly lower than other workers. The age range in our study is from 21 to 40 years with average age of 28 years. The age range in study of Gupta et al. ${ }^{16}$ is comparable with this. Left side is involved more commonly than right side (4:1) in our study. The incidence of embryonal carcinoma as a part of mixed germ cell tumors was $94.7 \%$, out of 19 cases 18 cases showed embryonal

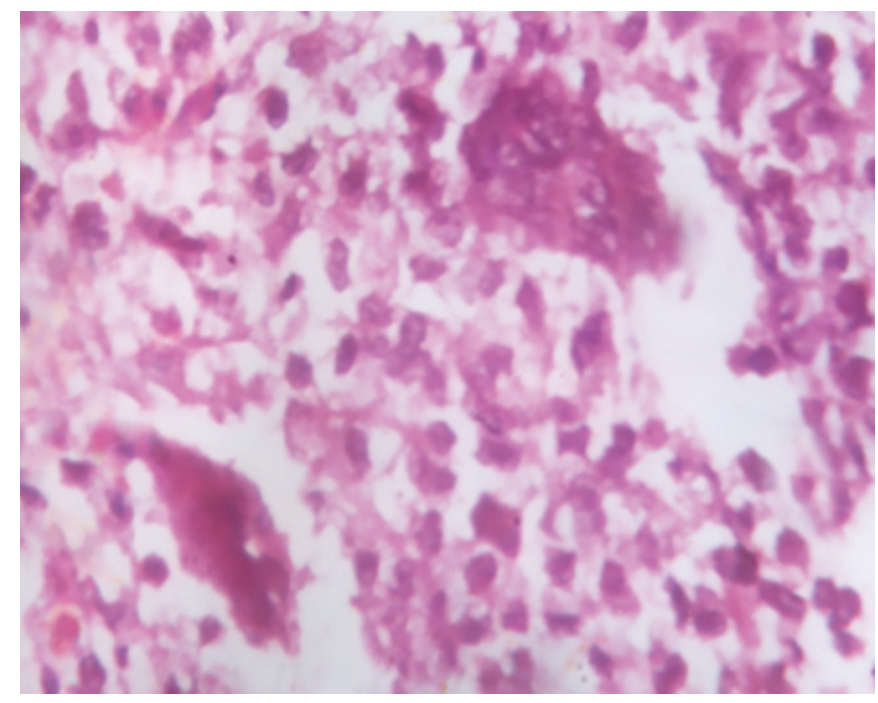

Fig. 2: Anaplastic seminoma with syncitio-trophoblastic giant cell ( $\mathrm{H}$ and $\mathrm{E}, 400 \mathrm{X})$

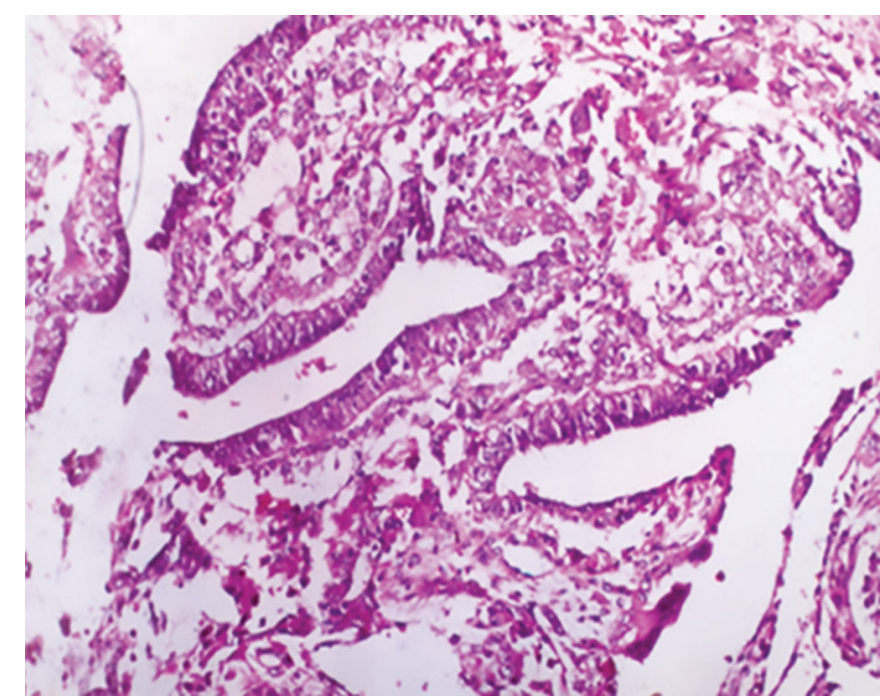

Fig. 3: Embryonal carcinoma ( $\mathrm{H}$ and $\mathrm{E}, 400 \mathrm{X})$

carcinoma as one of component. This high incidence is because of better sampling of orchidectomy specimen.

The third commonest tumor was teratoma constituting $6.8 \%$ of all testicular tumors, $11.7 \%$ of GCT of one histological type. The incidence of teratoma reported a lower incidence varying from 1.3 to $24.45 \%$. histologically all cases were of mature teratoma (Fig. 4) in our study. No case of immature teratoma and teratoma with malignant transformation was noted in our stutdy as the occurance of which is very veryrare. The age of our patient is 6 years, 12 years, 13 years, and 31 years is comparable to its common occurance in 1st to 3rd decade as described by Mostofi and Price ${ }^{6}$ and Aggarwal et al. ${ }^{23}$ reported $48 \%$ teratoma in prepubertal males.

Yolk sac tumor (Fig. 5) was found in 5.15\% of all testicular tumors and $5.7 \%$ of all GCT and was a component of $15.59 \%$ GCT more than one histological and $8.85 \%$ as pure yolk sac tumor. The incidence reported varied from 4 to $13.37 \%$ Age range in our study was 2 to 18 years. Aggarwal et al. ${ }^{23}$ have reported this tumor in 11 years old. There was clinical evidence of spread to mesentric lymph node in one case.

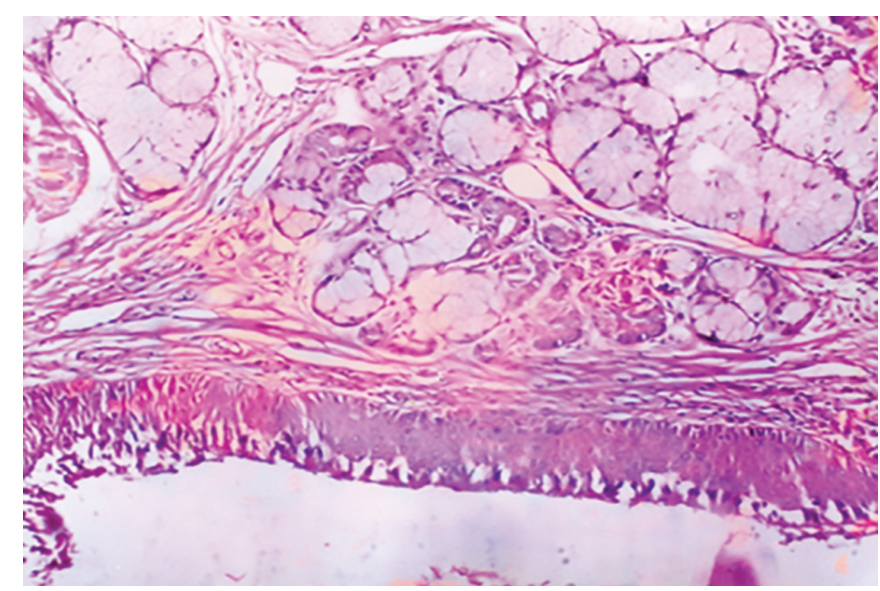

Fig. 4: Mature teratoma ( $\mathrm{H}$ and $\mathrm{E}, 400 \mathrm{X})$ 
Choriocarcinoma (Fig. 6) was seen only in one case out of 59 tumors and constituted $1.7 \%$. It was component of mixed germ cell tumor in two cases out of 19 cases of mixed germ cell tumor Collin and Pugh et al. ${ }^{21}$ reported none among 1050 cases while in american testicular tumor registry 18 cases of pure choriocarcinoma were listed in 6000 testicular tumors. The incidence noted by Miller and Seljel ${ }^{20}$ was $1.6 \%$. Gupta et al. ${ }^{15} 0.8 \%$, and Gupta et al. ${ }^{16} 2.2 \%$. Age of the case of pure choriocarcinoma was 25 -year and is comparable to its occurance in second and third decades as described by Mostofi and Price. ${ }^{6}$ and Shivade et al. ${ }^{24}$

Two cases of spermatocytic seminoma (Fig. 7) constitute $3.4 \%$ of 59 testicular tumors and $9.5 \%$ of 21 seminomas. Incidence varied between $1 \%$ to 9.35 to the age was 32 years and 50 years in these two cases with average age of 41 years. It occurs most commonly after the age of 50 years. Bergner et al. ${ }^{25}$ reported bilateral seminoma in a 30 year old patient. There was no clinical evidence of metastasis in our cases which is very very rare event in case of spermatocytic seminoma. Schoberg et al. ${ }^{26}$ have reported a case of metastasis of spermatocytic seminoma in axillary lymphnode. Bilateral involvement is more common in this type than in classical seminoma.No case of spermatocytic seminoma in cryptrorchid testis is reported so far including our study.

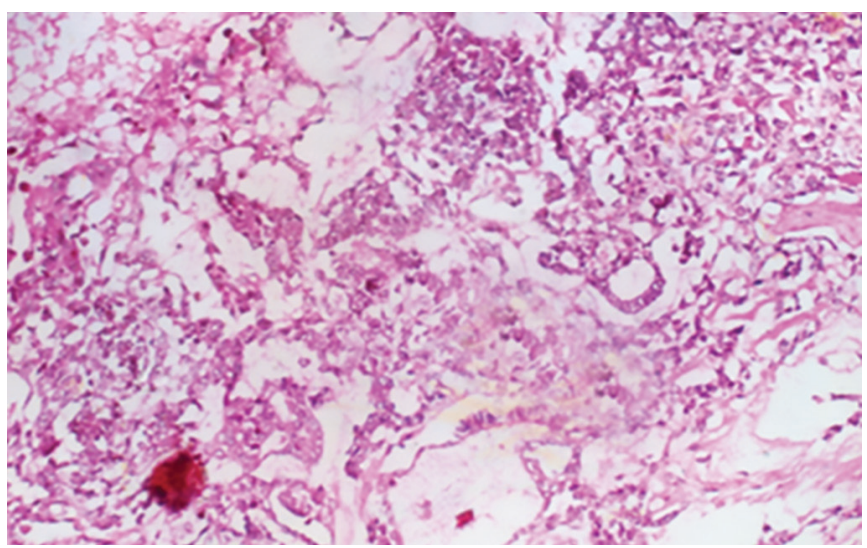

Fig. 5: Yolk sac tumor ( $\mathrm{H}$ and $\mathrm{E}, 100 \mathrm{X})$

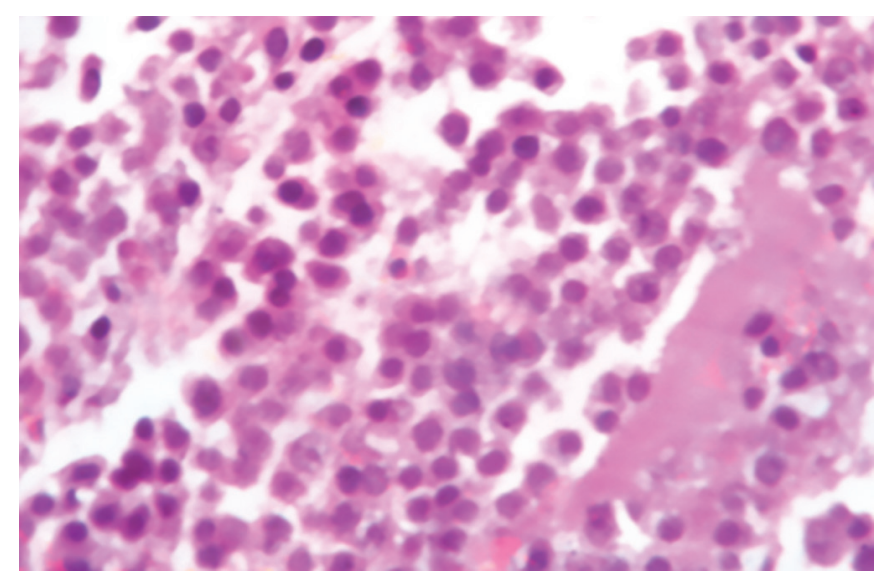

Fig. 7: Spermatocytic seminoma (H and E 400X)
Our study showed $32.2 \%$ of GCT of more than one histological type, the wide range of variation of this categories is seen in different studies $62.2 \%$ Mostofi and Price. $^{6}$ and $4.4 \%$ Gupta et al. ${ }^{16}$ except for spermatocytic seminoma, all other types may occur in combination, The incidence of germ cell tumors with more than one histological type is more because better sampling was done.

The most common combination encountered in this study was of teratoma and embryonal carcinoma (teratocarcinoma) (Fig. 8). Teratocarcinoma was also seen associated with yolk sac tumor $(n=2)$ or seminoma $(n=2)$ or choriocarcinoma $(n=1)$ The teratocarcinoma was the commonest combination in our study, i.e., 8 out of 19 tumors $(13.4 \%)$. This incidence is comparable to other workers. The age range varied from 17 to 52 years with average of 28.7 years. The age range of teratocarcinoma is 18 to 40 years with an average of 24.6 years. The maximum number of teratocarcinoma are seen in age range of 20 to 29 years similar findings are also noted by Gupta et al. ${ }^{15}$ Mostofi and Price. ${ }^{6}$ mentioned its common occurance in third decade but can occur earlier, in one of these cases, tumor involved crypt orchid test is which was initially corrected by orchiopexy. in one case teratoma was immature one while in another case of teratocarcinoma local spread to epididymis, spermatic cord and tunica was observed.

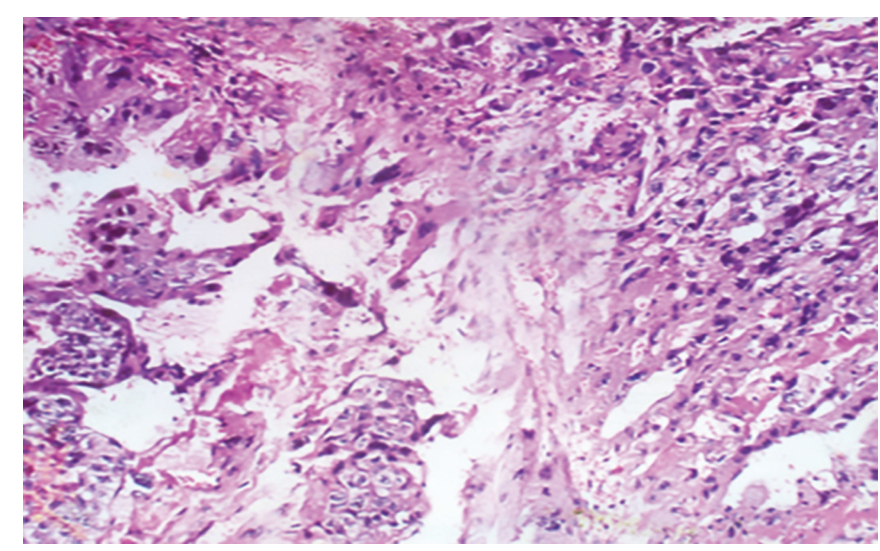

Fig. 6: Choriocarcinoma ( $\mathrm{H}$ and $\mathrm{E}, 100 \mathrm{X})$

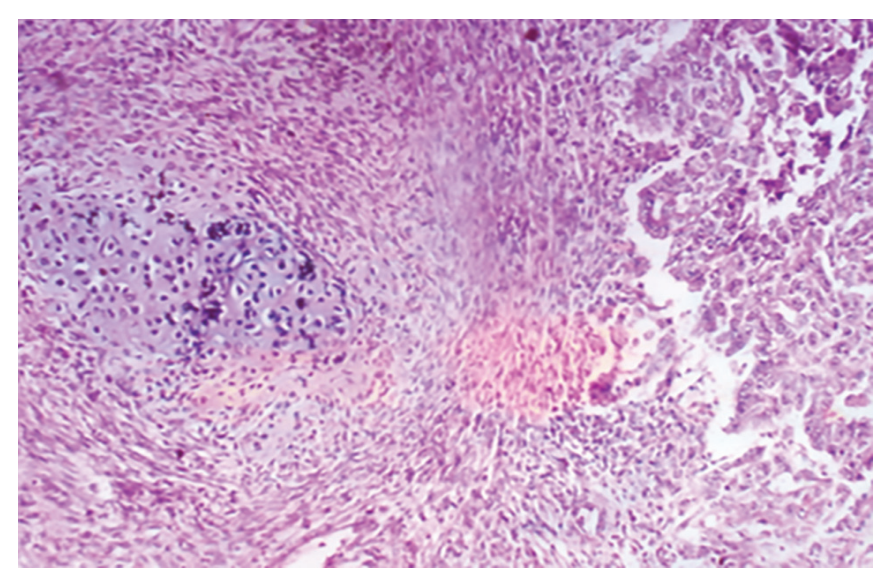

Fig. 8: Teratocarcinoma with teratoma (right) and (left) embryonal carcinoma, ( $\mathrm{H}$ and $\mathrm{E}, 400 \mathrm{X})$ 
We had total six cases of lymphoma out of 59 testicular tumor $(10.2 \%)$ In our series, there was one case of leukemic in-filtration of the testis in a known all and five cases of malignant lymphoma-non-Hodgkins type. The percentage of lymphoma in various studies ranged from 2.08 to $8.2 \%$. Our finding are comparable to Gupta et al. ${ }^{15}$ with Collin and Pugh et al. ${ }^{21}$ The age of patient with testicular lymphoma in our study were over 50 years except in two cases who were 8 years and 12 years old. The age range in series by Malhrotra et al. ${ }^{27}$ from 6 to 72 years, $50 \%$. of their cases are seen in 5 th decade. Gupta et al. ${ }^{15}$ also found maximum number of cases above 50 years in their study. Our study included one case of well defferentiated diffuse lymphocytic lymphoma and four cases of poorly differentiated differ lymphocytic lymphoma.

The sex cord stromal tumors include tumor of leydig, sertoli, granulosa and theca cell origin. As compared to the germ cell tumors, the stromal tumors are rare, we did not find the case of sex cord or stromal tumor. The incidence in other studies is as shown in Table 5. Gonadoblastoma is restricted almost exclusively to individuals with underlying gonadal disorder either pure or mixed gonadal dysgenesis or malepseudohermaphoridism.our study did not have such tumor.

We did not find any case of secondary or miscellaneous tumors like carcinoid tumor in tumors constitute $2.37 \%$ of all testicular tumors in study of Mostofi and Price. ${ }^{6}$

\section{CONCLUSION}

Our study concludes that histopathology remains the main tool in the diagnosis of testicular tumors which exhibited a varied clinicohistomorphological features and is similar to international literature. Germ cell tumors form the bulk of testicular tumors. Among the individual germ cell tumors, seminomas are the commonest followed by teratocarcinoma. The ages of patients with testicular tumors is varying from 2 years to 80 years. Testicular tumors are commonest in third and fourth decade of life. All the yolk-sac tumors are seen exclusively in children. The most common clinical presentation is swelling of the scrotum with some patients have associated pain and history of trauma. Cryptochidism is one of the important predisposing factor.

\section{ACKNOWLEDGMENT}

I would like to thank Mr Ashwin PS for his contribution to manuscript writing.

\section{REFERENCES}

1. Garner M.J., Turner MC, Ghadirian P, Krewski D: Epidemiology of testicular cancer: an overview: Int. J. Cancer: 2005; 116:331-339.
2. Epstein JI. The Lower Urinary Tract and Male Genital system, Testis and Epididymis. Robbins Pathologic basis of disease. 8th ed., Philadelphia. WB :2010,Ch.21:984-986.

3. Tick SK, Amin MB, Crarner HM, Lara R Uibright TM. The testis, paratesticular structures and male external genialia ; Silverberg' principles andpractice of surgical pathology and cytopathology. 4th edition: Churchiillivingstone: 2004, vol 2: Ch.34.

4. Dixon, FJ, Moore, RA: Tumors of the male sex organs. p. 45. Atlas of human pathology. Section 8, Fascicles 31 and 32. Armed Forces Institute of Pathology, Washington 1952.

5. Young. RH, Clement PB, Scully RE, The fallopian tube and broad ligament. In: Sternberg's diagnostic surgical pathology. Mills SE (ed.) 4th edition, Philadelphia, Lippincott Williams and Wilkins, 2004; vol 3: Chapter 57.

6. Mostofi FK, Price EB Jr. tumors of male genital system. Atlas of tumor Pathology series 2 Fascicle and armed forces institute of Pathology. Washington DC 1973.

7. Mostofi FK Sabin LH Histological typing of testis tumors. International Histological classification of tumors No. 16 WHO Geneva 1977.

8. Baade P, Carriere P, Fritschi L. Trends in testicular germ cell cancer incidence in Australia. Cancer Causes Control 2008; 19: 1043.

9. Shaw J. Diagnosis and treatment of testicular cancer. Am Fam Physician 2008, 77:469.

10. Shinagare AB, Jagannathan JP, Ramaiya NH, Hall MN, Van den Abbeele AD. Adult extragonadal germ cell tumors. AJR 2012, 195, 274.

11. Tongaonkar H. Testicular cancer: Current management and controversial issues. Indian J Urol 2010, 26, 63.

12. Rosai J. Male reproductive system. Rosai and Ackerman's Surgical pathology. 10th edition Mosby Elsevier, 2011:vol1: ch.18:1338-1362.

13. ChandanwaleS, Chawala R, Buch A, Dharawadkar A, Gore C, Rajpal M. Pathology of testis. Int J Pharm Biomed Sci. 2012, 3(4), 167-176.

14. Fischer CG, Waechter W, Kraus S, Perez EF, Weidner W, Dudeck J. Urologic tumors in the Federal Republic of Germany. Cancer 1998, 82, 775.

15. Gupta VP, Chopra HL. Nagpal 8L. Tumors of tee-tis. Ind. J. Pathol Microbiology. 1980:23:155-160.

16. Gupta SC, Sharma A. et al. Testicular tumors (A clinicopathological study) Ind. J. Surgery.1983;45: 664-672.

17. Deotra A, Mathur DR, Vyas MC. A 18 years study of testicular tumors in Jodhpur, western Rajasthan. J Postgrad Med 1994;40:68-70.

18. Mostofi FK, David CJ. Male reproductive system and prostate. Kissane JM. Anderson's Pathology. 8thEdn. St. Louis Mosby, 1985; 798-800.

19. Moghe KV, Aggrawal RV, Junnarkar RV. Tumors of the testis. Ind, J. Cancer.1970;7:90-97.

20. Miller A, Selielid P. Histopathologic classification and natural history of malignant testis tumors in Norway. Cancer 1971; 26;1:1054-1062.

21. Collins DH, Pugh RCB. Classification and frequency of testicular cancer. Br J Urol 1964, 36 (suppl 1), 1-11.

22. Damjanov I. Tumors of the testis and epididymis in Murphy W.M. (ed). Urologic Pathology Philadelphia 1989, 314-379.

23. Aggrawal PK, Wabal KM., Mehrotra RML. Testicular tumors in infancy and childhood. Indian J. Pathol Micro, 1976, 75-84. 
24. Shivade AV Kher AV et al. choriocarcinoma of testis. Report of 2 cases and review of literature. Indian J. Cancer: 1972, 75-78

25. Bergner DM. Duck GB. Rao M. Bilateral sequential spermatocytic seminoma. J. Urology 1980,12:565-566.
26. Schoberg TW Wittakar3. et al. Metastaticspermatocytic seminoma, J. Urology;1980:124:739-741.

27. Mechrotra RML. Wahal KM, Aggrawal PK. Testicular lymphoma. A clinicopathological study of 22 cases. Ind. J. Pathol Microbiology:1979;22:301-306. 